EESTI NSV TEADUSTE AKADEEMIA TOIMETISED, 31. KOIDE KEEMIA. 1982, NR. 4

ИЗВЕСТИЯ АКАДЕМИИ НАУК ЭСТОНСКОИ ССР. ТОМ 31 ХимИЯ, 1982, № 4

удК $628.394: 547.681$

М. ВОЛЛЬ, М. ГУБЕРГРИЦ, К. КУИВ, ЛИа ПААЛЬМЕ, Марина ТРАПИДО, Ннгеборг ВЕЛДРЕ, Айно ИТРА

\title{
ПРОБЛЕМЫ КАНЦЕРОГЕННОЙ ЗАГРЯЗНЕННОСТИ ЧУДСКО-ПСКОВСКОГО ОЗЕРА
}

Чудско-Псковское озеро в комплексе с впадающими в него многочисленными водотоками различной величины представляет собой важную в народнохозяйственном аспекте и уникальную экологическую систему, богатую разнообразной биотой. Так, в нем обитает свыше 35 видов рыбы, около 750 видов водорослей. На Чудское озеро приходится около $95 \%$ улова пресноводной рыбы в Эстонии [']. Одновременно в возрастающем масштабе озеро используется в рекреационных целях. В последние годы озеро рассматривается как важный перспективный источник питьевого и хозяйственного водоснабжения северо-восточного района Эстонской ССР и Таллина.

Исходя из вышеизложенного, тщательная и всесторонняя оценка состояния озера в самых разных аспектах и прогноз его изменения, основанные на анализе статистически достоверных природных и экспериментальных данных, представляются своевременными и необходимыми. В частности, необходимо обеспечить эффективную профилактику, охрану и организацию многолетнего народнохозяйственното использования системы и важнейших ее элементов, загрязненных канцерогенными веществами - специфичными продуктами деятельности человека - универсальными загрязнителями биосферы. В этом отношении немаловажным должен быть вклад не только биологов и гидрологов, но и химиков-исследователей, задачи которых мы уточним позднее. Укажем лишь, что предварительные исследования в этом направлении были проведены впервые в 1977-1978 гг. $\left[{ }^{2}\right]$.

В настоящей статье предпринята попытка обобщить результаты первого этапа систематического изучения канцерогенной загрязненности озера, проведенного по расширенной программе за 1979-1981 гг. совместными усилиями Института химии АН ЭССР и Института экспериментальной и клинической медицины Министерства здравоохранения ЭССР.

\section{Объекты, задача и методика исследования}

Для оценки состояния и прогнозирования загрязненности водоема необходимо располагать характеристикой: основных источников его загрязнения - впадающих водотоков (хотя бы в устье каждого из них), воздуха, атмосферных осадков и выбросов; распределения вредного вещества в водах - в поверхностном слое и, по возможности, на различных глубинах в донных грунтах; содержания его в важнейших элементах биоты - водорослях, рыбе, пллантоне и других водных организмах. На следующем этапе решения проблемы необходимо располагать сведениями не только о закономерностях накопления загрязнителя, но и об аккумуляции, путях и количественной характеристике 


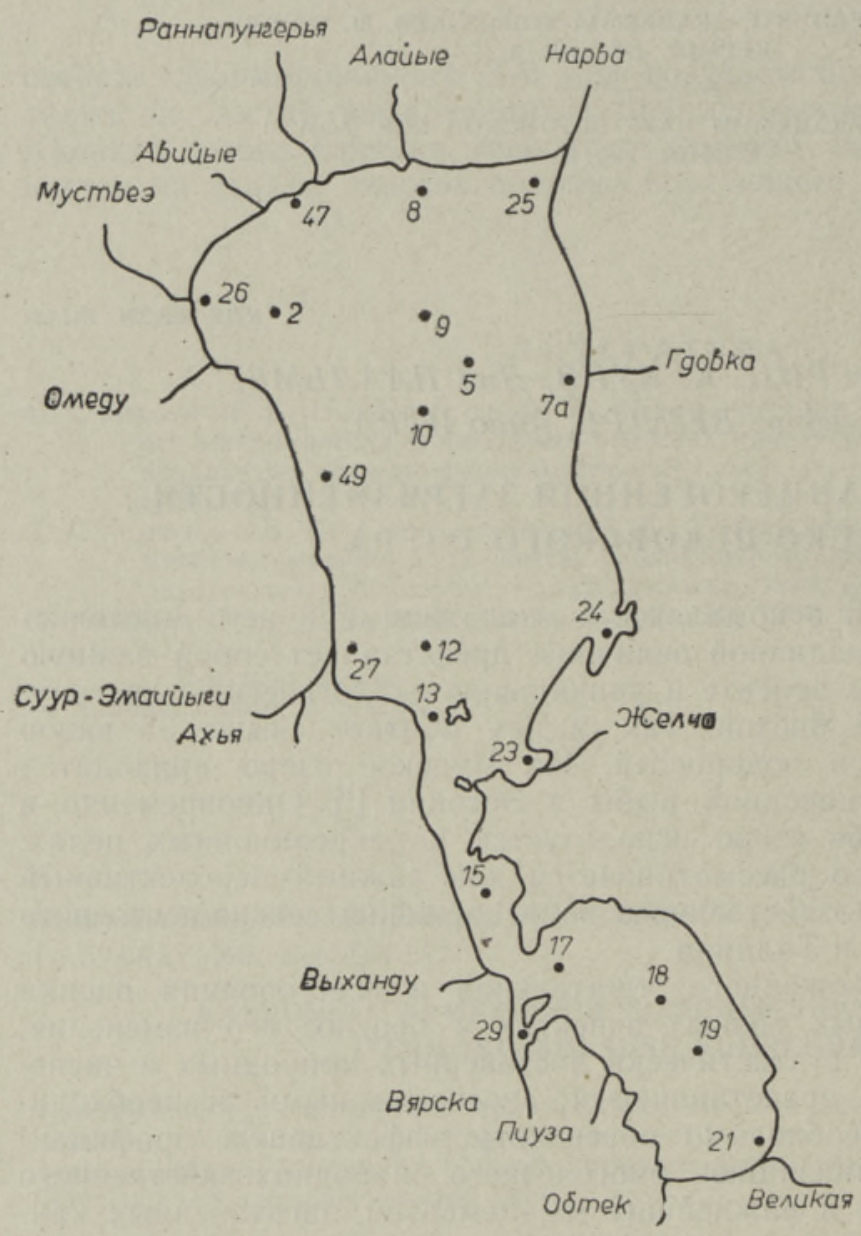

Рис. 1. Схема расположения точек отбора проб в ЧудскоПсковском озере.

вывода его из системы, а также о деградации вредного вещества в процессе самоочищения экосистемы.

Операции первого этапа и надлежало выполнить в данной работе применительно к Чудско-Псковскому озеру как объекту изучения и бенз (а) пирену (БП) как индикаторному веществу, с некоторой условностью представляющему канцерогенные полициклические углеводороды (ПАУ), загрязняющие водоем.

Детальная характеристика объекта приведена авторами в предыдущих сообщениях $[2,3]$ и на данном этапе не нуждается в уточнении. Схема изучаемого объекта с нанесенными на ней точками отбора проб по сетке Управления гидрометеорологии и контроля среды ЭССР, с которым авторы поддерживали контакт в процессе работы, представлена на рис. 1.

Основной задачей первого этапа было изучение распределения БП главным образом в важнейших физических элементах объекта (вода, донные грунты) для получения показателей, характеризующих их состояние в данный небольшой, но типичный для определенного сезона отрезок времени, а также за более длительный период. Таким образом, первая группа полученных показателей относится к данным по концентрации БП в поверхностном слое вод озера и связанных с ним наиболее крупных рек (впадающих или вытекающих из него), приуроченным к каждому сезону того или иного года. Добавим, что до настоящего времени систематические посезонные съемки распространенности БП на объекте не производились. Следует также заметить, что на первом этапе исследования озера данные по концентрации БП в поверхностном слое воды могут удовлетворить исследователя при создании общей картины загрязненности. .Причиной этому служит хорошее, как правило, перемешивание воды в озере, средняя глубина которого достигает всего 8,3 в Чудском и лишь 3,8 м в Псковском озере, а вода меняется в среднем в течение двух лет.

В показатели второй группы входят данные по концентрации БП в донном грунте и ее распределению не только по площади дна, но и 
по глубине. До настоящего времени исследования донных грунтов имели лишь предварительный характер, а систематический отбор диф. ференциальных проб был налажен лишь в 1981 г. после создания и освоения соответствующей аппаратуры. Наконец, чтобы получить предварительное представление о возможном вкладе атмосферного воздуха, т. е. атмосферных осадков и выбросов, в общее загрязнение озерной части экосистемы на протяжении зимнего сезона $1979-1980$ гг., произведен отбор проб снегового покрова в северной части Чудского озера для исследования на БП. Практическое отсутствие снега или неудовлетворительное состояние льда не позволили организовать такие работы на озере в остальные годы.

Отбор проб воды, донных грунтов и их подготовка к исследованию на содержание БП проводились по общепринятой стандартной методике [4] с той ли́шь разницей, что в качестве экстрагента был использован $\boldsymbol{H}$-гексан. Количественное же определение БП проводилось спектрально-люминесцентным методом с использованием эффекта Шпольского [5].

\section{Результаты исследования}

Основные результаты исследования в обработанном и весьма сжатом виде, учитывая большой объем полученных за три года материалов (свыше 300 проб воды и 120 проб грунтов), представлены главным образом в графической интерпретации на рис. $2-5$.

На рис. 2 охарактеризованы усредненные (главным образом относящиеся к летнему сезону) данные по содержанию БП в водах, вносимых в озеро важнейшими (13 из 32) впадающими в него водотоками и выносимых из северной части озера течением р. Нарвы. Как видно,

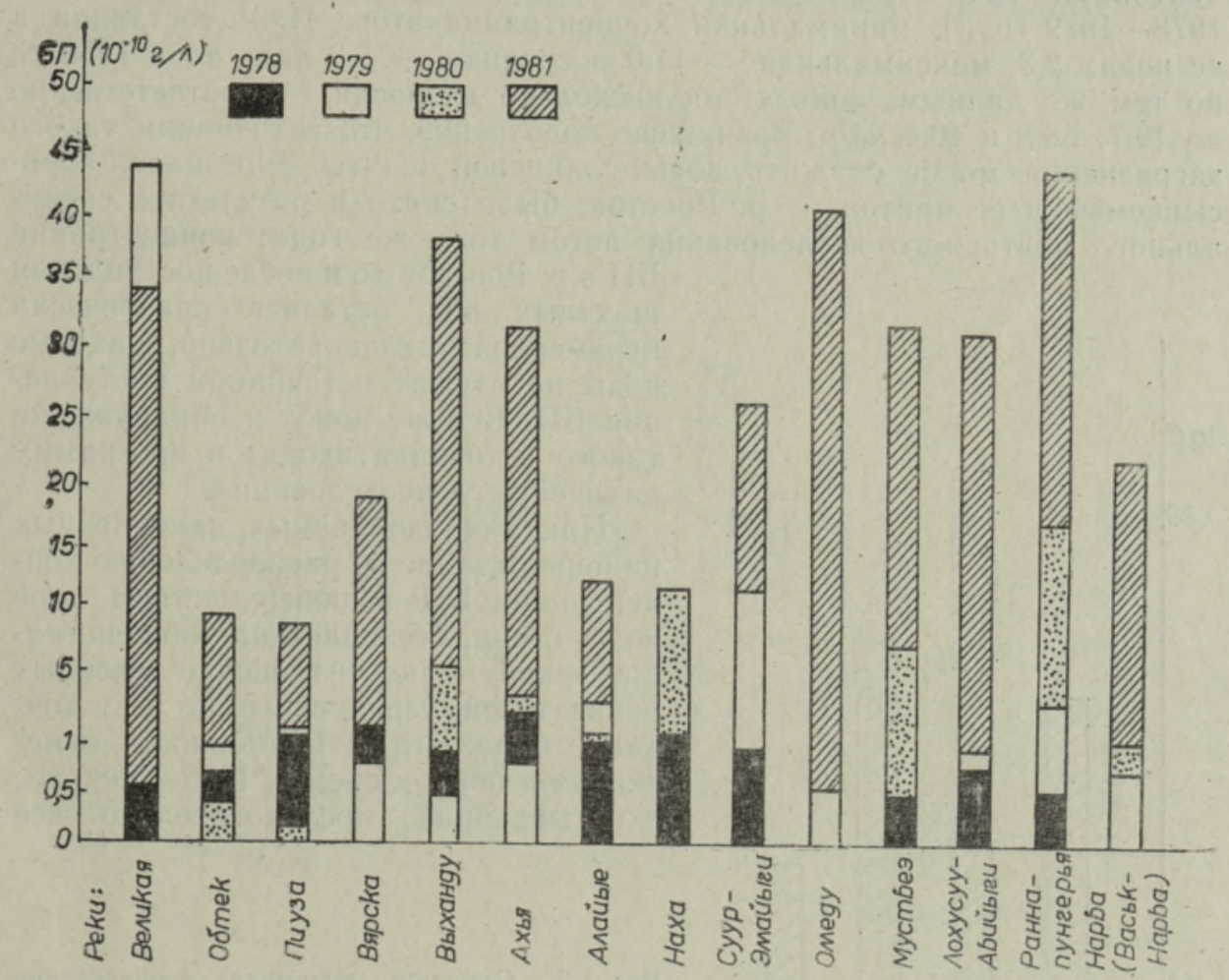

Рис. 2. Содержание БП в воде рек бассейна Чудского озера. 
за весь период наблюдений на этих объектах концентрация БП в поступающих водах, т. е. в одном из основных источников пополнения канцерогенного загрязнения озера, удерживалась в пределах санитарной нормы (для питьевых и рыбохозяйственных водоемов 0,005 мке/л). Однако из года в год этот показатель подвергается значительным изменениям, причем тенденция к увеличению или уменьшению загрязненности, более или менее закономерная, почти одинаково проявилась для всех изучаемых водотоков. При этом наиболее высокая концентрация БП в речных водах отмечалась в 1981 г. Поскольку это относится ко всем без исключения водотокам, можно предположить, что это явление обусловлено гидрологической обстановкой, сложившейся в 1981 т. вследствие большого количества осадков за весеннелетний период. Очевидно, с ливневыми стоками в водоемы поступило необычно большое количество БП. Тем не менее, такое вполне обоснованное предположение не исключает необходимости обратить серьезное внимание на организацию удовлетворительной очистки сточных вод, сбрасываемых обычно в некоторые водотоки.

Так, повышенным уровнем канцерогенного загрязнения (особенно в 1981 г.) отличаются реки Великая (площадь водосбора, по данным ['], $254000 \kappa м^{2}$ ) и Суур-Эмайыги (площадь водосбора $99960 \kappa \mu^{2}$ ), в которые поступают не только талые и ливневые воды из окружающей местности, но и сточные воды сравнительно крупных городов Пскова и Тарту. Из приведенного примера видно, что в данном случае сочетается действие двух основных факторов, обуславливающих возможное поступление БП в озеро с водотоками - загрязнение последних от крупных населенных пунктов и от смыва в сельской местности.

Продолжая анализ данных по водотокам, отметим, что в 1980 1981 гг. было зафиксировано также увеличение среднегодовой концентрации БП в р. Раннапунгерья (рис. 1, 2). Если, по данным 1978 - 1979 гг. [ $\left.{ }^{6}\right]$, минимальная концентрация этого ПАУ составила в ее водах 2,3, максимальная - 11,0 и средняя - 5,6 нг/, , то в 1980 г., по тем же данным, показатели несколько возросли - соответственно до 19,$7 ; 68,8$ и 40,4 на/ . Возникшее подозрение, что источником такого загрязнения могут служить воды сланцевой шахты «Эстония», сбрасываемые в ее приток - р. Роостоя, было снято в результате специального повторного исследования летом того же года: концентрация БП в р. Роостоя до и после поступления шахтных вод осталась практически

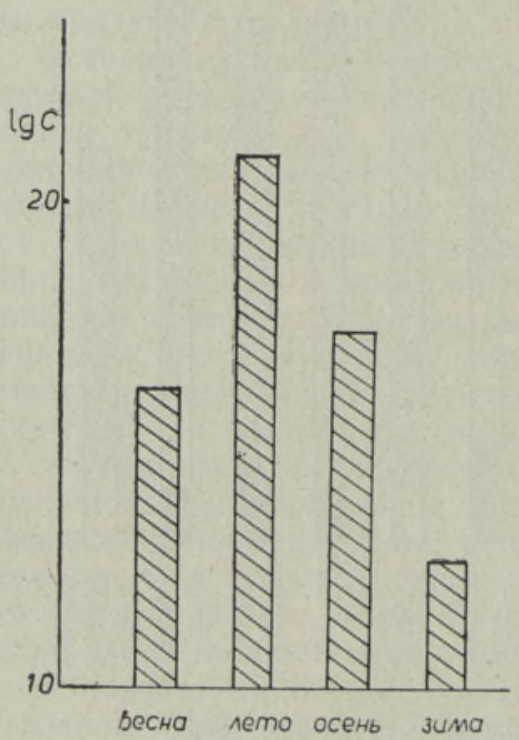
неизменной и, следовательно, шахтные воды не служат источником поступления БП. Все же поиск и обнаружение такого источника входят в программу дальнейшего исследования.

При анализе данных, накопленных на первом этапе по распределению концентрации БП в поверхностном слое воды озера, обращает на себя внимание закономерное изменение сезонных показателей, усредненных по всем точкам отбора. Эта закономерность, отмеченная в период съемок 1979-1980 гг., охватывающих последовательно все

Рис. 3. Сезонная динамика концентрации (C, $10^{-10}$ 2/л - средняя сезонная величина) БП в воде Чудского озера (1979-1980). 
четыре сезона, охарактеризована на рис. 3. Подобная тенденция в целом подтверждается и материалами, полученными в остальные годы первого этапа исследований, причем такая динамика сезонного изменения концентрации БП отличается от зафиксированной для других озер Әстонии [7]. В рассматриваемом нами примере максимум загрязнения приходится на лето, минимум - на зиму; весной и осенью концентрация БП имеет некоторые, почти сходные между собой промежуточные значения.

Распределение канцерогенной загрязненности вод поверхностного слоя по акватории озера за $1979-1981$ гг. показано на рис. 4. Из приведенного графика следует, что аналогично загрязненности речных вод, количество БП в воде в 1981 г. также возросло по сравнению с 1980 г. Таким образом, и на динамике изменения этого показателя в известной мере отражается общее воздействие гидрологического фактора, несколько осложненного в 1981 г. особенностями съемки в летнем сезоне. Съемка была проведена в экстремальных условиях, практически при полном штиле и большом количестве курсирующих на озере моторных судов. Это - не только промысловый, но и туристский и любительский рыболовный малый флот, интенсивное использование которого, как известно из литературы $\left[{ }^{8}\right]$, является немаловажным источником значительного канцерогенного загрязнения воды.

Сходная картина, отражающая результаты длительного периода загрязнения данной экосистемы БП, зафиксирована при изучении канцерогенной загрязненности донного грунта с заглублением в дно озера на $30-35$ см, с одновременным дифференциальным отбором и исследованием слоев толщиной 5 cм каждый. Постановка такого исследования, позволившего в значительной мере уточнить принципы распределения БП, оказалась возможной лишь при использовании специального пробоотборного аппарата, сконструированного и налаженного в

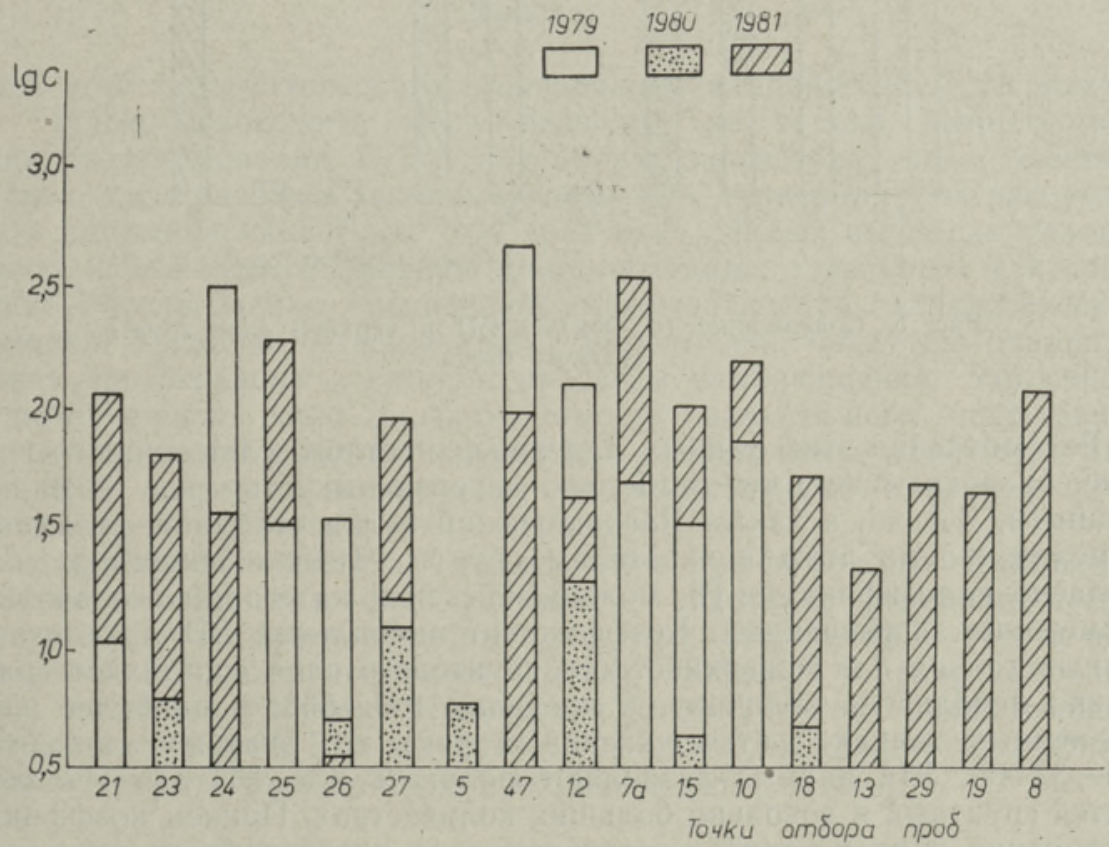

Рис. 4. Содержание $\left(C, 10^{-10} 2 / \Omega\right)$ БП в поверхностном слое Чудского озера в летний период. 
Содержание БП в грунтах Чудско-Псковского озера послойно (июль 1981 г.)

\begin{tabular}{|c|c|c|c|c|c|c|c|c|c|}
\hline \multirow{2}{*}{$\begin{array}{c}\text { Глубина } \\
\text { слоя, } \\
\text { см }\end{array}$} & \multicolumn{9}{|c|}{ Содержание по станциям, мкг/кट } \\
\hline & 24 & 21 & 18 . & 9 & 27 & 12 & 19 & 17 & 29 \\
\hline $\begin{array}{c}0-5 \\
5-10 \\
10-15 \\
15-20 \\
20-25 \\
25-30 \\
30-35\end{array}$ & $\begin{array}{r}22,0 \\
6,3 \\
0,6 \\
- \\
0,6 \\
2,3 \\
-\end{array}$ & $\begin{array}{r}24,3 \\
7,2 \\
20,7 \\
14,7 \\
7,2 \\
12,0 \\
-\end{array}$ & $\begin{array}{l}\overline{8,2} \\
3,8 \\
2,8 \\
1,4 \\
1,4 \\
-\end{array}$ & $\begin{array}{l}3,5 \\
1,2 \\
2,2 \\
\overline{0,6} \\
- \\
-\end{array}$ & $\begin{array}{r}16,2 \\
5,9 \\
2,5 \\
0,7 \\
0,7 \\
- \\
-\end{array}$ & $\begin{array}{l}2,9 \\
0,6 \\
1,9 \\
0,0 \\
0,3 \\
0,5 \\
1,1\end{array}$ & $\begin{array}{l}8,6 \\
9,9 \\
7,0 \\
4,8 \\
3,8 \\
4,9 \\
2,3\end{array}$ & $\begin{array}{r}10,8 \\
15,9 \\
10,5 \\
19,6 \\
8,3 \\
3,6 \\
1,2\end{array}$ & $\begin{array}{l}10,9 \\
11,2 \\
\overline{1,9} \\
0,8 \\
0,7 \\
-\end{array}$ \\
\hline
\end{tabular}

Институте химии АН ЭССР (авторы - М. Волль и Р. Эйскоп). В таблице приведены результаты исследования содержания БП в селективных пробах донных грунтов.

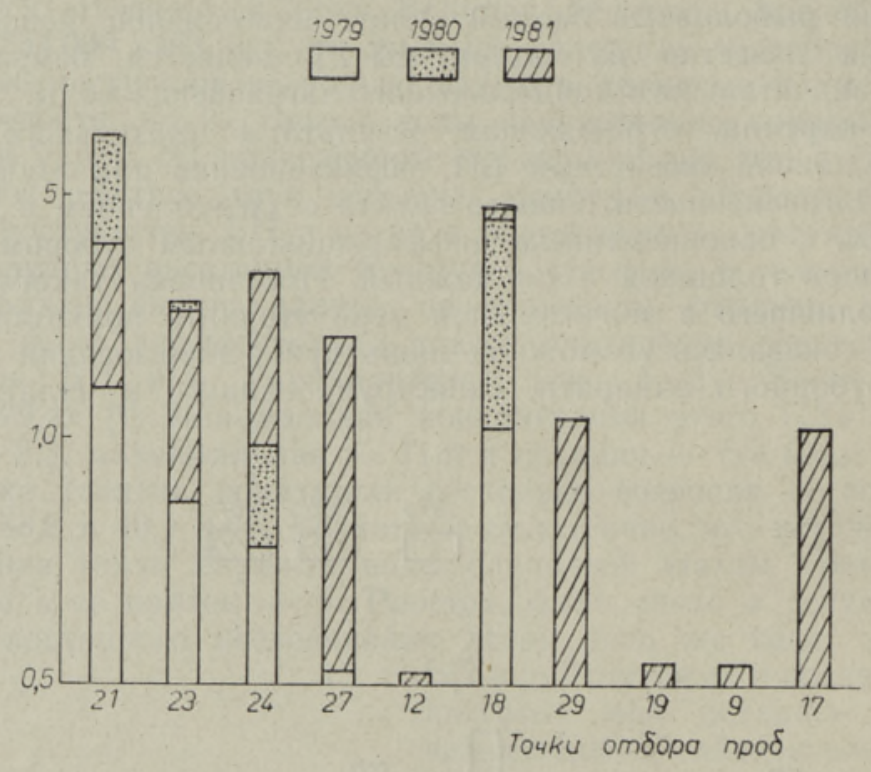

Рис. 5. Содержанне $(C$, мкг/кг) БП в верхнем слое грунта
Чуддского озера.

Рассмотрение этих данных для поверхностного слоя донного грунта (рис. 5) показывает, что стабильно загрязнены устья рек - Великой, Эмайыги, Желчи, а также Раскопельский залив (таблица, станция 24). В целом же по этим показателям грунты Чудско-Псковского озера, согласно классификации [" ${ }^{9}$, можно отнести к категории незначительно и умеренно загрязненных. Коэффициент накопления БП в малозагрязненных точках для поверхностного грунтового слоя составляет сравнительно небольшую величину, в пределах $160-560$; в наиболее же загрязненных точках (устья указанных рек) его значение доходит до 890 - 32 000. Эти данные позволяют полагать, что БП активно сорбируется грунтами в довольно больших количествах. Причем коэффициент накопления канцерогенного углеводорода в поверхностном слое грунта оказывается более значительным, чем при сорбции $a$-СПАВ $\left[{ }^{10}\right]$.

В данном случае количество сорбированного БП также определяется природой или характером грунта - в илистых отложениях оно 
оказывается, как правило, примерно на порядок величины выше, чем в песчаных грунтах. Дифференциальное исследование грунтов выявляет также значительный перепад концентрации БП при переходе от поверхностного слоя к следующему за ним уже через 5 cм в песчаном грунте (см. данные для станций 24, 27 в таблице) и практическое отсутствие градиента концентрации по глубине. В слое на глубине 15-25 см содержание БП на порядок величины ниже, чем в поверхностном слое грунта и примерно соответствует возможному фоновому уровню для обычных почв в данном регионе. В илистом грунте, особенно в местах сильного загрязнения системы (устье р. Великой, Псковское озеро) загрязненным оказывается весь слой (20 cм), в пределах которого концентрация БП практически не изменяется. Таким образом, исходя из характеристики канцерогенного загрязнения донных грунтов с учетом небольшой глубины озера (в некоторых экстремальных случаях) можно предположить реальную опасность вторичного загрязнения вод БП в результате обмена с поверхиостным слоем донного грунта.

В заключение остановимся на результатах предварительного определения канцерогенной загрязненности атмосферных выпадений, роль которых, несмотря на малые концентрации в них БП, может оказаться более значительной, чем можно предположить. Укажем в связи с этим, что, по данным ['], $84 \%$ воды поступает в озеро из впадающих рек, a $16 \%$ - из атмосферных осадков. В изученных нами отдельных снеговых пробах количество БП колебалось от 0,0108 до 0,0215 мка/л талой воды. Интенсивность выпадения БП в сутки, вычисленная по результатам анализа проб из северной части озера (район Муствеэ),

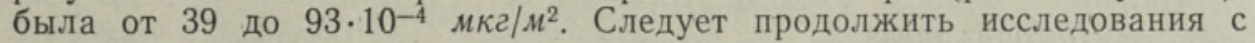
целью накопления статистически достоверных данных, контролируемых одновременно результатами непосредственных определений БП в воздухе.

\section{Выводы}

Первый этап систематического исследования канцерогенной загрязненности Чудско-Псковского озера позволил не только вскрыть ряд источников поступления БП в изучаемую экосистему, но и выявить некоторые качественные закономерности или тенденции его распределения и динамики изменения. При трактовке данных не всегда удается избежать искажающего влияния многочисленных случайных факторов, частично обусловленных спецификой складывающейся гидрологической обстановки. Также не удается еще с достаточной четкостью охарактеризовать протекающие в системе процессы самоочищения. Это свидетельствует прежде всего о необходимости дальнейшего расширения круга исследований с целью накопления достаточного количества статистических данных для перехода от качественной характеристики явлений к количественным закономерностям.

С целью профилактики на данном этапе нужно усилить требования к очистке сточных вод, сбрасываемых в водотоки, питающие озеро, обеспечить бесперебойную работу очистных сооружений; ограничить использование малого моторного флота (особенно в рекреационных целях); повысить уровень технической эксплуатации общественного рыболовецкото флота. Это обеспечит, как нам представляется, стабильное удовлетворительное состояние экологической системы. 


\title{
ЛИТЕРА Т У А
}

1. Mäemets, A. Eesti NSV järved ja nende kaitse. Tallinn, 1977.

2. Велдре И. А., Итра А. Р., Паальме Л. П., Губергриц М. Я., Тра пидо М. А., Ирха Н. И. Уровень бенз(а)пирена в воде и донных отложениях Чудского озера. - В кн.: Экспериментальная и клиническая онкология, Таллин, 1981, с. $53-59$.

3. Велдре И. А., Итра А. Р., Па альме Л. П. О возможном влиянии шахт. ных вод на содержание бенз(а)пирена в воде водоемов. (Респ. науч.-техн. конференция «Хозяйственный механизм рационального природопользования при добыче полезных ископаемых», Кохтла-Ярве, 1980). Таллин, 1980, c. $105-107$.

4. Ильницкий А. П. и др. Методические указания по отбору проб из объектов внешней среды и подготовка их для последующего определстия канцерогенных углеводородов. М., 1976.

5. Федосеев а Г. Е., Хе син а А. Я. Исследование квазилинейчатых спектров люминесценции для количественного определения ряда полищиклических углеводородов. - Ж. прикл. спектроскоп., 1968, т. 9, вып. 2, с. 282-288.

6. Велдре И. А., Итра А. Р., Па альме Л. П. О содержании канцерогенных полициклических ароматических углеводородов в водоемах сланцевого бассейна. (Тез. XVI науч. сессии по вопр. гигиены труда и профпатологии в сланцевой пром-сти). Таллин, 1981 , с. $10-11$.

7. Канцерогенные вещества в водоемах Эстонии. Таллин, 1979, с. 41.

8. Клубков Г. О роли судоходства в загрязнении водоемов канцерогенными углеводородами. - В кн.: Современные вопросы экспериментальной и клинической онкологии. М., 1975 , с. $16-19$.

9. Ильницки й А. П., Л ембик Ж. Л., Соленова Л. Г., Шаб ад Л. М. О распределенин канцерогенных углеводородов в пресноводных водоемах. - В кн.: Канцерогенные вещества в окружающей среде. М., 1979, с. 48-53.

10. Ирха Н., При й ман Р., Губергриц М. К вопросу о накоплении анионных поверхностно-активных веществ в природных водоемах и их количественном определении. - Изв. АН ЭССР. Хим., 1981, т. 30, № 4, с. 276-280.

\section{Институт химии \\ Академии наук Эстонской ССР}

\section{Поступила в редакцию 24/III 1982}

\author{
M. VOLL. M. GUBERGRITS, K. KUIV, Lia PAALME, \\ Marina TRAP!DO, Ingeborg VELDRE, Aino ITRA
}

\section{PEIPSI-PIHKVA JARVE KANTSEROGEENSEST SAASTATUSEST}

Suhteliselt lühikese ajavahemiku (1979-1981) jooksul kogutud andmete alusel on antud ülevaade Peipsi-Pihkva järve vesikonna saastatusest kantserogeensete polütsükliliste aromaatsete süsivesinikega indikaatoraine - 3,4-benso(a)püreeni alusel. On toodud viimase sisaldus vees ja põhjasetetes (viimaste puhul ka sügavuti) aastaajati. Põhilisteks saasteallikateks on Emajōgi, Velikaja ja Zeltša jõgi, laevaliiklus ning atmosfäärist sadenevad ühendid.

M. VOLL, M. GUBERGRITS, K. KUIV, Lia PAALME,

Marina TRAPIDO, Ingeborg VELDRE, Aino ITRA

\section{SOME PROBLEMS OF CARCINOGENIC POLLUTION OF LAKE PEIPSI}

The paper deals with the results of the first stage (1979-1981) of a systematic study of the carcinogenic pollution of L. Peipsi and some tendencies in the distribution of the indicating carcinogene - benzo(a)pyrene in its water and in the bottom soil. Some preliminary recommendations are given concerning the protection measures of that ecological system. 